\title{
Towards a contingent model of key staff retention: The new psychological contract reconsidered
}

\author{
Gregory Lee \\ School of Economic and Business Sciences, University of the Witwatersrand, \\ Private Bag 3, Wits, Johannesburg, Republic of South Africa \\ Email: 100greg@mentor.edcm.wits.ac.za
}

Received May 2000

\begin{abstract}
Theories and evidence of widespread changes in employment relationships abound in literature. The organisational environment is increasingly characterised by mandates of flexibility, reorganisation, reengineering and downsizing. As a result, traditional perceptions of what is owed between an employee and an organisation are subject to reappraisal. Such perceptions are encapsulated by the concept of the 'psychological contract'. Evidence suggests that in the transient global business environment, the psychological contract of employees and organisational representatives may be shifting towards a far more transactional paradigm. Transactional contracts describe perceptions that employment obligations are more short-term, work content based and less relational. However in the case of key employee groups, such transactional relationships may conflict with an organisation's need to retain its core skills and knowledge that form one of its only truly sustainable competitive advantages. Therefore divergent and varied psychological contracts increase the difficulty of decisions regarding the long-term retention of key employees. An explanatory model is therefore presented here, allowing for the various permutations and effects on key staff retention that may arise from such differing perceptions. Organisational solutions and research propositions are suggested for future research.
\end{abstract}

\section{Introduction}

Much evidence has been published in academic and commercial literature to suggest that significant changes have been forced upon employment relationships since approximately the mid-1980s, both globally (Cappelli, 1999) and in South Africa (Horwitz \& Franklin, 1996). It has been argued that these changes essentially describe a move by organisations away from the internal regulation of employment (which shields labour conditions from market realities) towards employment relationships which are increasingly exposed to market forces (Ehrlich, 1994).

Although apparently induced largely by broad economic trends, these changes have increasingly been analysed and framed in terms of individual psychological processes. Particularly prevalent are theories of the so-called 'psychological contract', which is not an actual contract but describes an individual's beliefs about the reciprocal obligations that exist in an employment relationship to which (s)he is party (Rousseau, 1989).

The aforementioned labour market changes, expressed as a 'new psychological contract' (i.e. a changed set of perceived employment obligations), have wrought several consequences. Not least is the growing perception that longterm staff retention must give way to the easy movement of employees in and out of the organisation according to strategic or individual need (Kissler, 1994; Tornow, 1988). Many organisations appear to have embraced flexibility for their workforce as a whole (Horwitz \& Erskine, 1995), and the end of 'job security' has been widely declared (O'Reilly, 1994; Hardijzer, 2000).
However, there is also no shortage of commentary (Benson, 1995) that continues to champion the vital role that a stable core of key staff play in organisational success (such employees are defined here as those who are truly core to the organisation's success, normally by dint of the key knowledge, skills, experience or abilities that they hold). The increasing realisation that such people are frequently one of the organisation's only truly sustainable competitive advantages (Thurow, 1992) means that the retention of key staff can still remain a vital organisational priority, although with potentially changed rules. It is therefore becoming increasingly difficult to know how the changing labour environment impacts upon both an organisation's need for and prospects of long-term staff retention.

Accordingly, after dealing with psychological contracts and their links to employee retention and thereafter expanding on the employment changes a simple model is presented to clarify the impact of varied employment perceptions upon key staff retention. The model builds upon recent theories that organisations may adhere to differing approaches to the employee-organisation relationship between and even within themselves (Lepak \& Snell, 1999), and similarly that different employees may have differing approaches and preferences despite a common social context. It is hoped that such a model will help organisations better understand and manage the nature and duration of the employment relationships with individuals who are key to the organisation's success and therefore worthy of individual analysis. Research propositions based on the model are suggested for future research in key staff retention. 


\section{The psychological contract in employment relationships}

In every employment relationship, actual contractual terms are formed through written, oral (explicit contracts) or tacit means (implicit contracts) that indicate agreement regarding certain mutual obligations. These actual terms are observable by third parties and enforceable in law. However, the very existence of conflict also indicates that, regardless of the actual terms, individuals to a contract have their own perceptions of what is owing between the employee and the organisation, which may differ from the actual terms and from each other (Rousseau \& Parks, 1993). These individually-held perceptions are known as 'psychological contracts' (i.e. the mutual obligations of employment as perceived in the mind of the individual, Rousseau, 1989).

Therefore, both an employee as well as the organisational decision-makers involved with that specific employee (managers, recruiters etc.) have individually-held perceptions, based on past interactions and social contexts, of what the employee owes the organisation and what is owed in return (Rousseau, 1989; Rousseau \& Parks, 1993). An employee may believe, for example, that in exchange for overtime (s)he has been promised extended leave, or a manager may believe that in exchange for extensive coaching an employee has committed to remain loyal to the organisation for some time.

Psychological contracts spring from a dynamic relationship, thus perceived obligations can be subjective and may change over time. Therefore, the perceptions of an employee and the organisational representatives involved may not agree. This differs from explicit or implied contracts, which exist because certain established patterns of agreed action have been worked out through written, spoken or acted means, leading to legal enforceability (MacNeil, 1985).

It is these psychological terms that will guide and characterise future behaviour. Therefore, perceived obligations (and not necessarily the actual contract) must be studied to understand workplace attitudes and behaviour (Schein, 1980).

Theory postulates that the terms or obligations described by psychological contracts differ according to the extent to which they are transactional as opposed to relational in nature (Robinson, Kraatz \& Rousseau, 1994; Rousseau 1990). Transactional obligations are relatively impersonal obligations essentially to do with economic exchange, and generally emphasise specific tasks, timeframes and monetary returns with little emphasis on extended relationship between the parties. Relational contracts, on the other hand, are rooted in an ongoing relationship, and are thus perceptions that long term, less defined, socioemotional obligations exist, which may be characterised by attributes such as trust and commitment (Shore \& Tetrick, 1994). These two aspects are generally seen as existing on a continuum, therefore a psychological contract that is high on one type of obligation will be low on the other (MacNeil, 1985).
Psychological contracts, and especially their transactional vs. relational balance, have particular pertinence to the retention of employees, as discussed next.

\section{Psychological contracts and employee retention}

It should be noted that, in this context, staff 'retention' is a concept not only concerned with stemming the dysfunctional turnover of key employees but also (equally important) with the behaviours and attitudes that are evidenced if they stay (Flowers \& Hughes, 1973). It is important that those who stay are doing so for the right reasons, and with the right attitudes and behaviours. A retention plan that does not attend to both runs the risk of retaining employees who may not want to be there, or even stay despite feelings of antipathy and frustration towards the organisation. Therefore, a retention plan must not only retain employees but also engage them in a way that leads to positive, productive attitudes and behaviours for the period of employment.

In this regard especially, perceived obligations and their consequences play an important role. The psychological contract lies at the heart of the employment relationship. The perceptions of its terms by both employees and organisational agents are likely to direct much of the observable attitudes and behaviour within an employment relationship (Schein, 1980), including turnover and retention.

The exact processes by which turnover and retention behaviours are affected by psychological contracts seem to be varied. Psychological contracts have for example been linked to commitment (Millward \& Hopkins, 1998), organisational culture (Nicholson \& Johns, 1985; see Sheridan, 1992 for impact on turnover), unmet expectations (Pearson, 1995; Robinson, 1996) as well as betrayal of trust (Robinson, 1996; Robinson \& Rousseau 1994). All these constructs have links to both turnover and on-the-job behaviour. Empirical research also confirms that perceived violations of the psychological contract increase intended or actual turnover, and negatively affect work attitudes and behaviour (Cavanaugh \& Noe, 1999; Robinson, 1996; Robinson \& Rousseau, 1994; Turnley \& Feldman, 1999).

The nature of the interaction between psychological contracts and turnover can generally be explained by the extent to which contracts are perceived as relational as opposed to transactional. By definition, relational contracts are those where mutual obligations of a longer-term nature are perceived, indicating a tendency towards retention. Transactional contracts however are those where mutual obligations of a more short-term nature are perceived, with the absence of long-term commitments, thus indicating a tendency towards flexibility and easy disengagement (Rousseau, 1990). As discussed next, changes in employment contracts appear to be occurring with regard to the relational vs. transactional balance, with attendant consequences for staff retention. 


\section{The 'new psychological contract'}

Prior to approximately the 1980 s, organisations perceived labour competitiveness to exist in a stable workforce with lifelong retention of employees (Cappelli, 1995; Horwitz, 1991). As a result, many organisations (especially large corporations) actively sought to insulate their workforce from the demands of the market by a somewhat artificial system of internal controls and mechanisms such as promotion and reward systems based on seniority.

The 'old' psychological contract that accompanied this belief was essentially a system of perceived relational obligations. Employers generally offered employees almost absolute job security, consistent rewards, career management through steady training and advancement and long term company-defined benefit plans (retirement), in exchange for the expectation that employees would give all their loyalty and effort to the company for the very longterm (Ehrlich, 1994). Individual employees and organisational decision-makers alike genuinely perceived these as the mutual obligations of a healthy employment relationship, and acted accordingly.

However, the 1980s (later for many South African organisations) saw the beginning of broad economic pressures such as the increasing globalisation of business, changing demographics and information technology. These effectively shifted the sources of competitiveness (Ehrlich, 1994; Kissler, 1994). Organisations implemented increasingly stringent efforts to improve their productivity, including widespread restructuring, downsizing and flexibility drives that stripped organisations to a minimum of staff, with widespread terminations of mid-management in particular (Cappelli, 1992 \& 1999; Horwitz \& Franklin, 1996). The emphasis has shifted to one of maximum productivity, commitment and efficiency from a minimised workforce (Burack, Burack, Miller, \& Morgan, 1994; Hiltrop, 1996; but see Coldwell, 1993). In many cases, long term company loyalty to employees has been replaced by the demands of having a flexible workforce that can adjust quickly to market needs, regardless of who needs to be hired, terminated or changed. Essentially, labour markets appear to have become far more market-driven or externalised (Cappelli, 1995).

It should be noted that neither the old contract nor the changes are necessarily representative of all (or even most) companies. However, where they have occurred, the wholesale reduction of job stability essentially rewrote the perceived obligations of psychological contracts. Employers had made it clear through action that, with the new business environment, they could no longer be expected to owe employees the same obligations that had previously been perceived as core to the employment contract. Employees, initially shocked and depressed, have to varying degrees responded by adjusting their own perceptions of mutual obligations. Literature reports the realisation by many employees that they must discard the old assumptions of mutual loyalty and to some extent take responsibility for their own careers, without dependence on any one organisation (Tornow, 1988; Hardijzer, 2000). Practitioners and academics have therefore observed and hypothesised the birth of a whole new psychological contract, with significantly different perceived obligations on both sides of the employment relationship (Kissler, 1994; Robinson \& Rousseau, 1994).

The new psychological contract can be described simply as a movement towards a far more transactional psychological contract, and less reliance on relational (long term) obligations (Cavanaugh \& Noe, 1999). This relationship is one of self-reliance for employees - it has been described as a shift from paternalism (where the organisation regulates and protects the entire labour relationship) to partnership (employees assume significant responsibility for their careers and jobs).

With the emphasis on self-reliance and partnership in creating value, several changes in human resource systems have been observed in companies (see Horwitz \& Erskine, 1995 and Horwitz \& Franklin, 1996 for South African parallels). Organisational forms have become more fast and flexible, with narrowly defined jobs increasingly giving way to teamwork, project orientations and flat hierarchies amongst other innovations (Bridges, 1994). This pushes responsibility for contribution more onto employees, who also gain more interesting and enriching work by being increasingly empowered with strategic information, autonomy, rotations and often some flexibility in work times and content (Waterman, Waterman \& Collard, 1994). Staffing for such systems is increasingly based on shortterm strategy (O'Reilly, 1994), allowing for flexible hiring, firing and changing of employees as well as contingent staffing as needed (despite questions as to the efficacy of this in a team based environment, Milner, 1995). Organisations are less able to develop careers over time, and are increasingly becoming 'buy' type firms that hire or fire talent as needed. As a result, career development and concepts of job tenure have changed significantly. Employees are expected to be more responsible for their own careers (Waterman et al., 1994), with the help of organisations but without expectations of long-term job security (researchers have thus observed shifts in employee loyalty from the company to the profession or career (Cavanaugh \& Noe, 1999)). Organisations will help employees be more 'employable' in the general workplace by providing interesting, enriching and productive work, coaching and mentoring, career guidance, empowerment and aid in acquisition of generic skills (training is increasingly up to employees but more portable). Long-term retention is therefore increasingly unlikely where these concepts have taken hold. In addition, pay and performance appraisal are increasingly reflective of true employee value, and less of seniority (thus increased use of incentive and skill-based pay (Horwitz \& Erskine, 1995)). Companies are also increasingly abandoning expensive benefit plans with fixed outcome levels (Lucero \& Allen, 1994). Instead, they are capping their own contributions and giving employees more responsibility for contributing as well as more say in levels and types of benefits (as with defined contribution plans (Ippolito, 1995)). This allows for flexibility and portability of benefits without tying employees to the organisation and vice versa (Barringer \& Milkovich, 1998). 
Even long-term stock plans tied to retention may give way to the needs of flexibility.

These changes are consistent with agency theory, which postulates that expectations of shorter relationships will lead to more outcome-based contracts and less behaviour-based contracts. This is because with shorter expected tenures, information asymmetry between the employee and the organisation is likely to be higher (making it harder for the organisation to predict whether employees will act in its interests, Eisenhardt, 1989).

The new psychological contract is certainly not a resolved concept in employment relations. Although the changes do appear to have occurred fairly widely in places, in some organisations it may appear only in parts, or not at all in others (Benson, 1995). Many anomalies and differences therefore exist that expose complication. This may be especially true in the case of key staff retention, as discussed below.

\section{Anomalies in current psychological contracts}

Different organisations and employees may ascribe to differing employment models. Not all situations or reactions fit the description given above of employment changes. Differences often occur, especially as regards key staff retention.

For example, while many organisations have embraced a more transactional contract with all staff, many other organisations or individual decision-makers within companies continue to advocate and work towards the longterm retention of a core of key employees, even in the midst of cutting other staff, and in apparent contradiction to the new psychological contract (Kissler, 1994; Horwitz \& Franklin, 1996 for South Africa). This emphasis on retention may merely be a contemporary strategic need, exacerbated by currently tight labour markets for skilled workers, but alternatively may be a more general belief held by those employers that relational contracts (with key staff specifically) are generally the best approach for the organisation.

Even within organisations, it is possible for organisational decision-makers to perceive a more relational contract with one key employee and a more transactional contract with another. These differences will depend on the strategic role and value of each individual staff member (Shore \& Tetrick, 1994).

Finally, reports regarding reactions of employees to the changes are also mixed. Some employees, especially key employees with mobility, appear to have embraced the flexibility of the more transactional approach (Waterman et al., 1994). In fact, the scarcity of skilled employee groups in many economies (including South Africa) means that some key staff often have significant bargaining power, and anecdotal evidence suggests that they are increasingly using it to their advantage (Bencivenga, 1997). On the other hand, others appear unable or unwilling to accept the new regime, and despite all pressures to the contrary prefer and demand a more relational, secure employment relationship.
Researchers report loss of commitment and trust, negativity, turnover and even sabotage from such employees who have had change forced upon them (Wiesner, Vermeulen \& Littler, 1999 for South Africa). Others may have succumbed to a state of shock and disillusionment following major changes. This leads to a temporary breakdown of perceptions about mutual obligations and a vacuum of uncertainty and paralysis, consistent with Rousseau \& Wade-Benzoni's (1994) 'Transitional' or 'No Guarantees' psychological contract that permeates organisations in change times - transactional contracts usually emerge from the confusion.

Each individual labour relationship within an organisation may therefore differ with regards to the nature of both the employer and employee psychological contracts. To the extent that the new psychological contract is true, retention of key staff can no longer be approached with the traditional uni-dimensional approach that stresses across-the-board minimisation of turnover. Rather a contingency model suggesting alternative strategic approaches for differing contractual approaches is suggested, as discussed next.

\section{A contract-sensitive contingent retention model}

This paper has proposed that the retention of key staff potentially remains an important area of concern for organisations. However, in many cases the need to render employment relationships flexible and competitive makes retention planning difficult.

A contingency model has therefore been developed to define and explain the different permutations that may arise from the particular intersection of the psychological contracts of an employer and employee in any given employment relationship. Essentially it is a strategic model which attempts to define and understand the fit between the organisation and its human resources, and implement appropriate contracting strategies.

This strategic typology examines a single employment relationship in which there is one individual key employee (with a particular standpoint towards the psychological contract), and one or more employer agents (managers, recruiters etc, each with their own standpoints towards the psychological contract that define what is hopefully a fairly uniform organisational approach to the employment relationship). Armed with an understanding of the psychological contract of the employee and the preferred approach of the organisation, decision-makers can use this model to understand the potential problems and issues, and address these in a retention plan.

In the model (Figure 1) employee and employer perceptions of reciprocal obligations may be high or low on their acceptance of the new psychological contract terms. Therefore there is a continuum in each case, with extremes for the employee being (1) Employee high on acceptance of the new psychological contract, corresponding to a more transactional contract (flexible, short-term, monetary employment relationships preferred) versus (2) Employee low on acceptance of the new psychological contract, 
corresponding to a relational contract (traditional, longterm, relational employment preferred);

The continuum for employers has similar extremes (Rousseau, 1990), running from (1) Employer high on acceptance, corresponding with the Miles \& Snow (1980) strategic organisational approach of a buy firm (which seeks to buy in the skills it needs with a minimum of attachment, corresponding with the transactional contract), to (2) Employer low on acceptance, corresponding with the Miles \& Snow (1980) strategic type of a make firm (which seeks to grow and develop employees over the long term with loyal relationships, therefore the relational contract).

The strategic typology examined here is cosmetically similar to that examined by Shore and Barksdale (1998), which
The 'Full Retention' Paradigm is the easiest paradigm to describe, as it essentially correlates with the traditional 'old psychological contract' as described earlier. Both employer and employee are low on the terms of the 'new' contract, and the relational aspects of the employment relationship may be indulged in full. The company, as per its own wishes, should enter into a regular and full retention program that anticipates loyalty and continuance from employees who are similarly inclined towards stability. Long-term compensation options (such as pension or provident funds and stock plans) can be implemented. Internal career development and company-specific training can receive significant investment with relative surety of return. Employee participation in management structures may be feasible. The whole range of retention possibilities

Low (relational)

Employee acceptance of new psychological contract

High

(transactional)

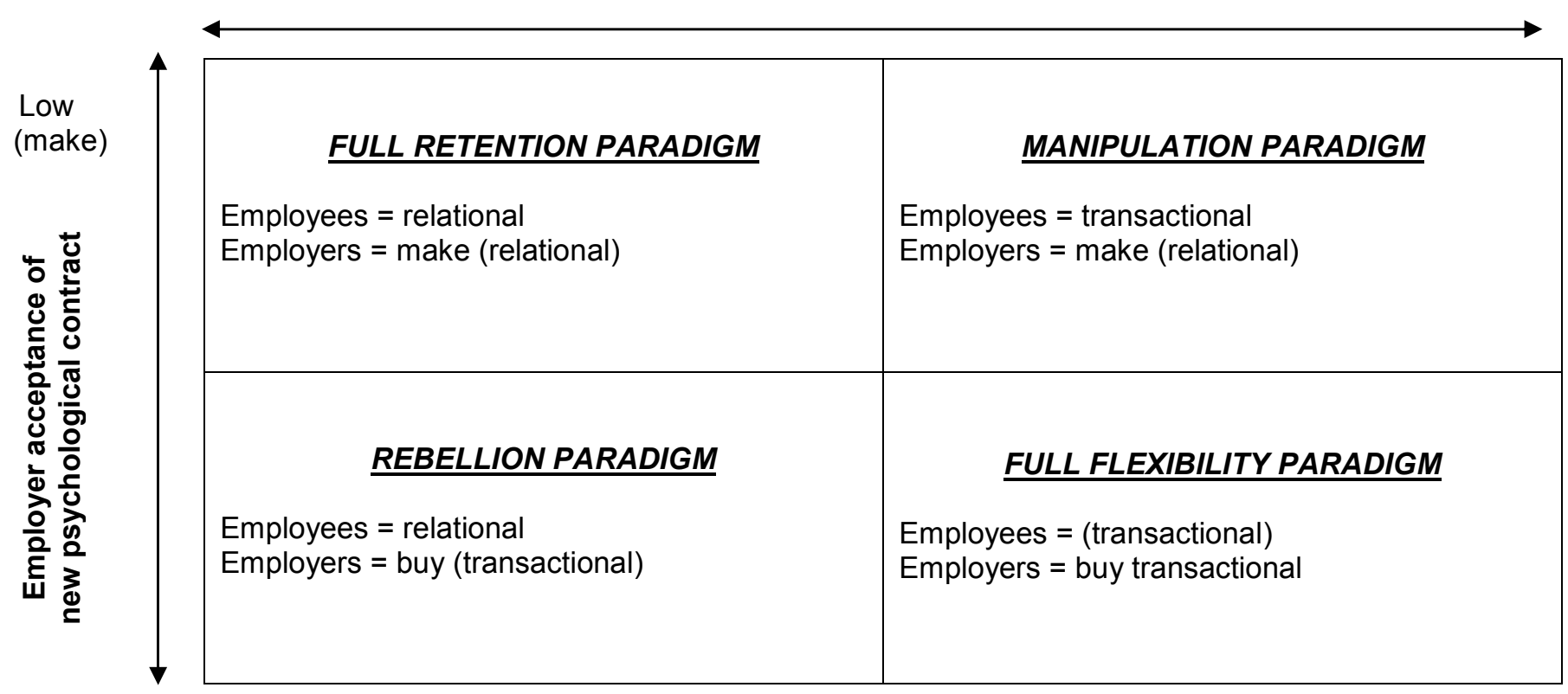

High

(buy)

Figure 1: Contingency model of key employee retention

looked at an employee and employer exchange obligations from the specific viewpoint of the employee's perspective. However while the model examined here retains the employee perspective on his/her own psychological contract, it matches it with the employer's own view of his/her contract, a significant difference (which does indeed lead to different hypotheses).

As seen in Figure 1, four possible permutations or paradigms are proposed depending on the particular combination of employee and employer perceptions of reciprocal obligations. Each describe differing retention situations, with particular implications for the organisation (thus the two negative names, describing potentially negative implications). cannot be fully described here, but the general conclusion to be drawn is that the company can expect a long-term return on any investment into a retention program. Therefore:

Research Proposition 1: Actual turnover and intent to turnover will be lowest for 'Full Retention' relationships (see Proposition 7 for extension)

The 'Full Flexibility' Paradigm describes the full effect of the 'new psychological contract', whereby the whole gamut of new employment changes is embraced as optimal by both sides. The employment relationship is transactional in nature, which implies a certain level of natural turnover. It is proposed here that conventional retention programmes and practises should be all but abandoned in favour of fully flexible relationships that minimise the entry and exit transaction costs that arise from employee turnover, which 
can now be expected and planned for. The impact on human resource systems correlates with those discussed earlier under the new psychological contract. As discussed there, many organisations do embrace elements of this paradigm, but often without a true understanding of whether employees support the new contract (as is the case here) or not (as with the next scenario). In this type of relationship, employees are getting what they expect, therefore negative consequences will be fairly low:

Research Proposition 2: Employees in 'Full Flexibility' relationships will have higher job satisfaction and commitment than those in 'Rebellion' relationships (see below).

The 'Rebellion' Paradigm describes the possible situation encountered when employers are high in their acceptance of the 'new' psychological contract (and are acting on that acceptance), but employee acceptance is low. The paradigm assumes that employers are acting upon a strategic mandate of flexibility and a casting away of any norms of loyalty (the new psychological contract), whereas employees still perceive obligations of and wish for a stable, loyal and longterm job environment.

The rebellion scenario has already occurred in many organisations that have embraced downsizing and the full range of attendant changes, but have been left with a demoralised and unsettled workforce (Wiesner et al., 1999). It often corresponds with the theories of perceived psychological contract violation, which is increasingly wellresearched (Cavanaugh \& Noe, 1999; Robinson \& Morrison, 2000; Robinson et. al., 1994; Robinson, 1996; Robinson \& Rousseau, 1994). Violation theory states that, because of the trust-based relational component of psychological contracts, breach of perceived obligations result in deeper reactions than those observed in the case of merely unmet expectations. Perceived violation of psychological contracts may result in 'deeper and more intense responses, akin to anger and moral outrage' (Rousseau, 1989:128). Research indicates that possible reactions that may result from perceived violation include (1) intentions to quit and actual turnover (Cavanaugh \& Noe, 1999; Robinson, 1996; Robinson \& Rousseau, 1994), (2) movement away from perceived relational obligations of employees and towards perceived transactional obligations (which are more 'mercenary' and short term by definition, Robinson et al., 1994), (3) lower positive employee contributions such as performance, civic virtue etc. (Robinson, 1996) and (4) lower job satisfaction (Cavanaugh \& Noe, 1999). Sabotage may even occur. It is called the 'rebellion' paradigm because it describes an acted, conscious, or subconscious friction between employer and employee that may erode all aspects of the employment relationship, not just those parts changed by the new psychological contract. Therefore:

Research Proposition 3: There will be a higher incidence of rebellion behaviours (described above) for the 'Rebellion' type relationships than those of any other.

It should be noted that this paradigm describes negative consequences given a lack of corrective action by an aware organisation. The results need not necessarily be negative however - the very purpose of this model is to help identify the likely scenario and its consequences and therefore to plan for human resource interventions. Having identified the likelihood of a strong rebellion scenario, a well-managed change process can be implemented, which will minimise damage and maximise the gains (see Rousseau, 1996 for such a change process). Lucero \& Allen (1994), in the context of benefits (but generally applicable), suggest strategies such as (1) changing employee expectations, (2) focusing on alternative and better ways of satisfying employee needs or (3) increasing employee participation (thus bringing about increased understanding of organisational rationales).

The 'Manipulation' Paradigm describes the case where an employee is high in his/her acceptance of the 'new' psychological contract (and is acting on that acceptance), but employer acceptance is low. Thus employees no longer perceive loyalty as being a requirement, but desire flexibility and employability through multiple careers etc. (the new psychological contract), whereas employers wish to have a strong core of loyal employees whom they can retain, train and invest in for a long-term return on investment.

Again, this scenario describes negative consequences that may be averted through foresight and change processes, although care must be taken to understand potential consequences. If the organisation is unaware of its employees' real expectations, it may try for traditional retention devices, but find turnover actually increasing as a direct result of the retention program. For example, a restricted stock plan may actually cause employee turnover, as those who expect a short tenure may wish for more liquidity in their compensation, and not be willing to submit to such time restrictions. Therefore:

Research Proposition 4: The use of retention programs will be negatively related to intent to turnover for 'Full Retention' relationships, but positively related to intent to turnover for 'Manipulation' relationships

An organisation that is aware of an employee's preference for a transactional relationship, but that desires retention, may try to maximise the utility of the employment experience for the employee, hoping to keep him/her for as long as possible. This entails giving the freedom and flexibility that the employee desires. It may include an emphasis on portable training (not too organisation specific), high base pay and performance incentives (necessitating a good performance management system), defined contribution or external benefits and other devices such as job rotation or enrichment to 'maximise the experience'. This may work well in some cases, but will almost invariably be a high cost approach as employees eventually leave. The paradigm is therefore termed a 'Manipulation' one as employers may increasingly be forced to follow the dictates of employees in order to retain them. Manipulation behaviours might include employees frequently renegotiating terms of employment or low incidences of disciplining for behaviours such as absenteeism. Tight markets for key labour groups - as 
experienced in South Africa - accentuate this problem, as replacement is difficult and costly (Cappelli, 1999). It should be noted that some manipulation behaviours may also occur in a 'full retention' relationship as organisations are attempting retention in both (however rarely in the buytype relationship). Therefore:

Research Proposition 5: Manipulation behaviours (as described above) will occur most frequently for 'Manipulation' type relationships, second most frequently for 'Full Retention' relationships and least for the buy-type organisation paradigms.

A more proactive option for firms is to place more emphasise on the recruiting and selection functions, in order to ensure that employees entering the workforce are a better fit for the organisation, and thus likely to match the longterm and loyalty-based approach of their employers (Hiltrop, 1996).

Research proposition 6: There will be a lower incidence of manipulation behaviours in organisations with advanced recruiting and selection programs designed for employeeorganisation fit (such as realistic job previews).

Based on the above conclusions regarding turnover, research proposition 1 can be extended. 'Rebellion' relationships clearly have the potential for highest turnover, due to worker dissatisfaction. In the middle, 'Manipulation' relationships would seem to have the potential for producing less turnover than 'Full Flexibility' relationships in any given period due to higher organisational inducements. Thus:

Research Proposition 7: Actual turnover and intent to turnover will be lowest for 'Full Retention' relationships, second lowest for 'Manipulation' relationships, third lowest for 'Full Flexibility' relationships and highest in 'Rebellion' relationships

Essentially, this contingency model seeks to minimise the costs of labour relationships by identifying the optimal contract to be entered into between a key employee and the organisation. The determination of employer and employee standpoints towards the employment relationship is a vital step. Put in the language of transaction cost economics, the minimisation of information asymmetry between employers and employees will enable bargaining to occur with maximum efficiency, and the optimal solution (contract) to be found (Milgrom \& Roberts, 1992). An optimal solution may range from flexibility to retention, and include any number of managerial adjustments in-between. Since an accurate understanding of psychological perceptions towards the employment relationships is vital, this step is discussed in more detail next.

\section{Ascertaining employee psychological contracts}

Some methods by which organisational decision-makers may ascertain employee perceptions include simple talks and regular communication efforts such as meetings, surveys or interviews.
Another possible method for ascertaining a particular employee's stance is through screening (Milgrom \& Roberts, 1992). Here, an organisation can discover the privately held information of an employee (in this case the perception of mutual obligations) by offering a variety of alternatives which would appeal to differing types of persons. The employee's choices are therefore assumed to be an indication of whether (s)he perceives mutual obligations of a relational or transactional nature. An example of such a screening method might be in the choice of compensation. If employees are offered a selection of long and short-term compensation elements (such as how much of their own pay to invest in stock plans) then their relative choices may describe the nature of their perception towards the employment relationship. In this case it is possible that employees who choose to tie themselves into long-term stock plans prefer a relational contract. Similarly, an employee's choices in the area of benefits (especially pensions) may indicate his or her stance

Although at first it may seem impractical and costly to have to ascertain the perceptions of individual employees, it is submitted that key employees are frequently subject to individual analysis due to their worth (as occurs with oneon-one mentoring or tailored compensation). The individual analysis of their contracts is no less possible or desirable (Shore \& Tetrick, 1994).

\section{Ascertaining the psychological contracts of organisational agents}

It is no less necessary to ascertain the perceived mutual obligations of those people who represent the organisation. It is unfortunately possible that, because of the individual nature of psychological contracts, different employer agents may present differing messages to employees as they represent the organisation (Shore \& Tetrick, 1994). It is necessary to assume however that there is some uniformity as regards messages given to the single employee in question.

Note that messages may differ between employment groups or individuals. In fact, theories of a 'dual internal labour market' assume that some firms choose to have core employees, towards whom employers perceive relational obligations, and periphery employees such as a temporary 'buffer' workforce designed to react to strategic need, towards whom only transactional obligations are perceived (Mangum, Mayall, \& Nelson, 1985). The important point is that messages presented to individual employees need a level of consistency for the model to have any reliability (Ehrlich, 1994).

\section{Conclusion}

Organisations rely on the quality and efficiency of the human and intellectual capital at their disposal, particularly in the case of key employees. The retention of key staff therefore remains a potentially valid and important strategic choice, despite the increasing rationale for flexibility in organisations. However, it is becoming increasingly difficult to understand and foresee the consequences of retention 
decisions. Rapid changes in business environments have wrought complex alterations in the psychological contracts of employees and organisational agents. It is crucial for organisations to understand that the perceptions of individuals are powerful determinants of behaviour that require understanding and skilful management. The contingent model presented in this article is a vital step in helping organisations to contract with maximum efficiency through an informed understanding of employee reactions, and ultimately to create an optimal fit between the organisation and its key staff. As similar theories are proposed and expanded, organisations will be better equipped for a future that promises constant change and increasingly less certainty.

\section{References}

Barringer, M.W. \& Milkovich, G.T. 1998. 'A theoretical exploration of the adoption and design of flexible benefit plans: A case of human resource innovation', Academy of Management Review, 23(2):305-324.

Benson, J. 1995. 'Future employment and the internal labour market', British Journal of Industrial Relations, 33(4):603-608.

Bridges, W. 1994. 'The end of the job', Fortune, Sept 19:46-51.

Burack, E.H., Burack, M.D., Miller, D.M. \& Morgan, K. 1994. 'New paradigm approaches in strategic human resource management', Group and Organization Studies, 19(2):141-159.

Cappelli, P. 1992. 'Examining managerial displacement', Academy of Management Journal, 35(1):203-217.

Cappelli, P. 1995. 'Rethinking employment', British Journal of Industrial Relations, 33(4): 563-602.

Cappelli, P. 1999. The new deal at work. Boston: Harvard Business School Press.

Cavanaugh, M.A. \& Noe, R.A. 1999. 'Antecedents and consequences of the new psychological contract', Journal of Organizational Behavior, 20: 323-340.

Coldwell, D.A.L. 1993. 'Business ethics and the bandwagon effect: An analysis of downsizing in the South African industrial situation', South African Journal of Business Management, 24(1): 18-22.

Ehrlich, C.J. 1994. 'Creating an employer-employee relationship for the future', Human Resource Management, 33(3):491-501.

Eisenhardt, K.M. 1989. 'Agency theory: an assessment and review’, Academy of Management Review, 14(1):57-74.

Flowers, V.S. \& Hughes, C.L. 1973. 'Why employees stay', Harvard Business Review, July-Aug: 53-64.
Hardijzer, C. 2000. 'Forging new careers in the changing world of work', People Dynamics, Feb: 36-40.

Hiltrop, J.M. (1996). 'Managing the changing psychological contract', Employee Relations, 18 (1):36-49.

Horwitz, F. 1991. Managing resourceful people. Cape Town: Juta \& Co.

Horwitz, F.M. \& Erskine, V. 1995. 'Labour market flexibility in South Africa: A preliminary investigation', South African Journal of Labour Relations, 19(2):26-47.

Horwitz, F.M. \& Franklin, E. 1996. 'Labour market flexibility in South Africa: Researching recent developments', South African Journal of Labour Relations, 20(1):3-39.

Ippolito, R.A. 1995. 'Toward explaining the growth of defined contribution plans', Industrial Relations, 34(1):1-20.

Kissler, G.D. 1994. 'The new psychological contract', Human Resources Management, 33(3):335-352.

Lepak, D.P. \& Snell, S.A. 1999. 'The human resource architecture: Toward a theory of human capital allocation and development', Academy of Management Review, 24(1):31-48.

Lucero, M.A. \& Allen, R.E. 1994. 'Employee benefits: A growing source of psychological contract violations', Human Resource Management 33(3):425-446.

MacNeil, I.R. 1985. 'Relational contract: what we do and do not know', Wisconsin Law Review: 483-525.

Mangum, G., Mayall, D. \& Nelson, K. 1985. 'The temporary help industry: A response to the dual internal labor market', Industrial and Labor Relations Review, 38(4):599-611.

Miles, R.E. \& Snow, C.C. 1980. Designing strategic human resources systems, Organizational Dynamics: 36-52.

Milgrom, P. \& Roberts, J. 1992. Economics, organisation and management. Englewood Cliffs, NJ: Prentice-Hall

Millward, L.J. \& Hopkins, L.J. (1998). 'Psychological contracts, organizational and job commitment', Journal of Applied Social Psychology, 28:1530-1556.

Milner, S. 1995. 'Where do we go from here?' British Journal of Industrial Relations, 33(4):609-615.

Nicholson, N. \& Johns, G. 1985. 'The absence culture and the psychological contract - who's in control of absence?', Academy of Management Review, 10:397407.

O'Reilly, B. 1994a. 'The new deal: What companies and employees owe one another', Fortune International, June 13:28-33. 
Pearson, C.A.L. 1995. 'The turnover process in organizations: An exploration of the role of met-unmet expectations', Human Relations, 48(4):405-420.

Robinson, S.L. 1996. 'Trust and breach of the psychological contract', Administrative Science Quarterly, 41:574-599.

Robinson, S.L., Kraatz, M.S. \& Rousseau, D.M. 1994. 'Changing obligations and the psychological contract: A longitudinal study', Academy of Management Journal, 37(1):137-152.

Robinson, S.L. \& Morrison, E.W. 2000. 'The development of psychological contract breach and violation: A longitudinal study', Journal of Organizational Behavior, 21:525-546.

Robinson, S.L. \& Rousseau, D.M. 1994. 'Violating the psychological contract: not the exception but the norm', Journal of Organizational Behavior, 15:245-259.

Rousseau, D.M. 1989. 'Psychological and implied contracts in organisations', Employee Rights and Responsibilities Journal, 2(2):121-139.

Rousseau, D.M. 1990. 'New hire perceptions of their own and their employers obligations: A study of psychological contracts', Journal of Organizational Behavior, 11:389-400.

Rousseau, D.M. 1996. 'Changing the deal while keeping the people', Academy of Management Executive, 10(1):5061.

Rousseau, D.M. \& Parks, J.M. 1993. 'The contracts of individuals and organisations', Research in Organisational Behaviour 15:1-43.

Rousseau, D.M. \& Wade-Benzoni, K.A. 1994. 'Linking strategy and human resource practises: How employee and customer contracts are created', Human Resource Management, 33(3):463-489.

Schein, E.H. 1980. Organizational psychology. Englewood Cliffs, NJ: Prentice Hall.

Shore, L.M. \& Barksdale, K. 1998. 'Examining degree of balance and level of obligation in the employment relationship: a social exchange approach', Journal of Organizational Behavior, 19:731-744.

Shore, L.M. \& Tetrick, L.E. 1994. 'The psychological contract as an exploratory framework in the employment relationship.' In Cooper, C.L. \& Rousseau, D.M. (Eds.) Trends in Organizational Behavior, Vol 1, Somerset, NJ: John Wiley \& Sons.

Thurow, L. 1992. Head to head. New York: William Morrow \& Company, Inc.

Tornow, W.W. 1988. 'Contract redesign', Personnel Administrator, Oct: 97-101
Turnley, W.H. \& Feldman, D.C. 1999. 'The impact of psychological contract violations on exit, voice, loyalty and neglect', Human Relations, 52 (7):895-922.

Waterman, R.H., Waterman, J.A., \& Collard, B.A. 1994. 'Toward a career-resilient workforce', Harvard Business Review, July-Aug: 87-95.

Wiesner, R., Vermeulen, L.P. \& Littler, C.R. 1999. 'Survivor syndrome: Effects on middle managers in South Africa', South African Journal of Economic and Management Sciences, 2(3):390-406. 